Aktuell, nachhaltig, praxisrelevant

\title{
Berlin: Kongress Pflege 2016
}

_ Am 22. und 23. Januar 2016 trafen sich zum 21. Mal mehr als 1.500 Entscheider aus Pflege, Gesundheitswirtschaft und Berufspolitik sowie Pflegende aller Versorgungsbereiche auf dem Kongress Pflege im Maritim proArte Hotel in Berlin. Der Kongress von Springer Medizin zählt zu den bekanntesten Branchentreffs für alle in der Pflege und im Gesundheitswesen Beschäftigten. Neben der Fachfortbildung ist der Kongress eine optimale Plattform für Networking und professionellen Austausch. Es ging um Themen wie Patientenrechtegesetz, pflegerische Sterbebegleitung oder Vorsorgevollmacht. Im Mittelunkt der Diskussionen standen in diesem Jahr allerdings die zahlreichen neuen Gesetze sowie die Reformen in der Pflegeausbildung.

Wie in jedem Jahr war der der Pflege-RechtTag ein echter Zuschauer-Magnet. Auch die Juristische Veranstaltung für Fachanwälte für Medizin und Soziales, der schon zum zweiten Mal stattfand, hat sich bereits etabliert und erstreckte sich über beide Kongresstage. Pflegende Angehörige nutzen die speziell für ihre Interessen organisierte Veranstaltung der SBK-Betriebskrankenkasse.

Am Abend des 22. Januars waren alle Kongressbesucher zur großen Kongressparty eingeladen. In ihrem Rahmen wurde zum

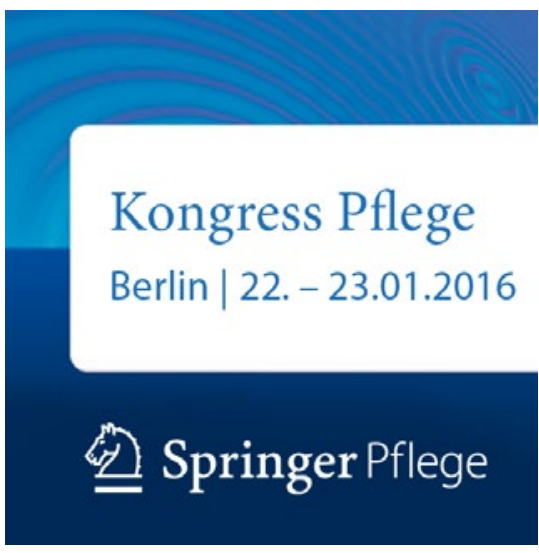

5. Mal der Pflegemanagement-Award für Nachwuchsführungskräfte verliehen.

www.gesundheitskongresse.de

\section{Sächsischer Pflegerat}

\section{Fachtag zum Pflegeberufegesetz}

— Der Sächsische Pflegerat schaltet sich mit einem Fachtag in die aktuelle Debatte um das geplante Pflegeberufegesetz ein. Am 25. Februar 2016 veranstaltet er an der Evangelischen Hochschule Dresden den Fachtag "Zukunft des Pflegeberufes - Wohin steuert diePflege mit einer generalistischen Ausbildung?".

Ziel des Fachtages ist es, mit Pflegenden, Praxisanleitern, Führungskräften und Mitarbeitern der Berufsfachschulen zum aktuellen Stand des Gesetzvorhabens ins Gespräch zu kommen und aus den Ergebnissen des Fachtages Empfehlungen der Praxis für die genaue Umsetzung des Gesetzes zu erarbeiten. Ausdrücklich möchte der Pflegerat den kritischen Diskurs zum geplanten Gesetz führen und mit Kritikern und Befürwortern zum Fachtag ins Gespräch kommen. Anmeldeschluss ist der 14 . Februar.

www.pflegerat-sachsen.de

\section{Neues Pflegeberufsgesetz}

\section{Bundesregierung beschließt Gesetz} den Gesetzentwurf zur Reform der Pflegeberufe beschlossen. Bundesgesundheitsminister Hermann Gröhe und Bundesfamilienministerin Manuela Schwesig haben den Entwurf des Pflegeberufsgesetzes anschlieBend in der Bundespressekonferenz vorgestellt. Menschen, die sich für den Pflegeberuf entscheiden, soll eine qualitativ hochwertige und zukunftsfähige Ausbildung geboten werden, die ein breites Spektrum an Einsatz- und Entwicklungsmöglichkeiten eröffnet. Die bisherigen drei Ausbildungen in der Altenpflege, der Gesundheits- und Krankenpflege sowie der Gesundheits- und Kinderkrankenpflege sollen reformiert und $z u$ einem neuen einheitlichen Berufsbild zusammengeführt werden. Der neue Pfle-
- Das Bundeskabinett hat am 13. Januar geberuf wird damit zum größten Ausbildungsberuf in Deutschland mit über 133.000 Auszubildenden. Die Finanzierung der dreijährigen Ausbildung wird bundeseinheitlich geregelt. Für Auszubildende ist sie künftig kostenfrei. Außerdem erhalten alle Auszubildende eine angemessene Ausbildungsvergütung. Zudem soll die neue, generalistische Pflegeausbildung auf einen Einsatz in allen Arbeitsfeldern der Pflege vorbereiten. Damit ist ein Wechsel zwischen den einzelnen Pflegebereichen leichter. Zugleich werden den Pflegekräften damit wohnortnahe Beschäftigungsmöglichkeiten und zusätzliche Einsatz- und Aufstiegsmöglichkeiten eröffnet.

www.bmg.bund.de

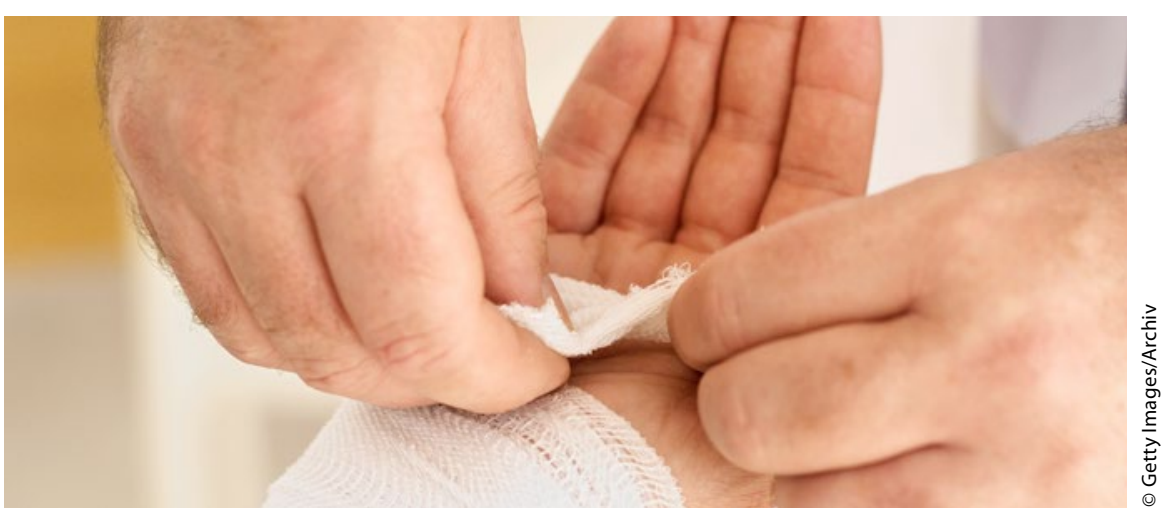

